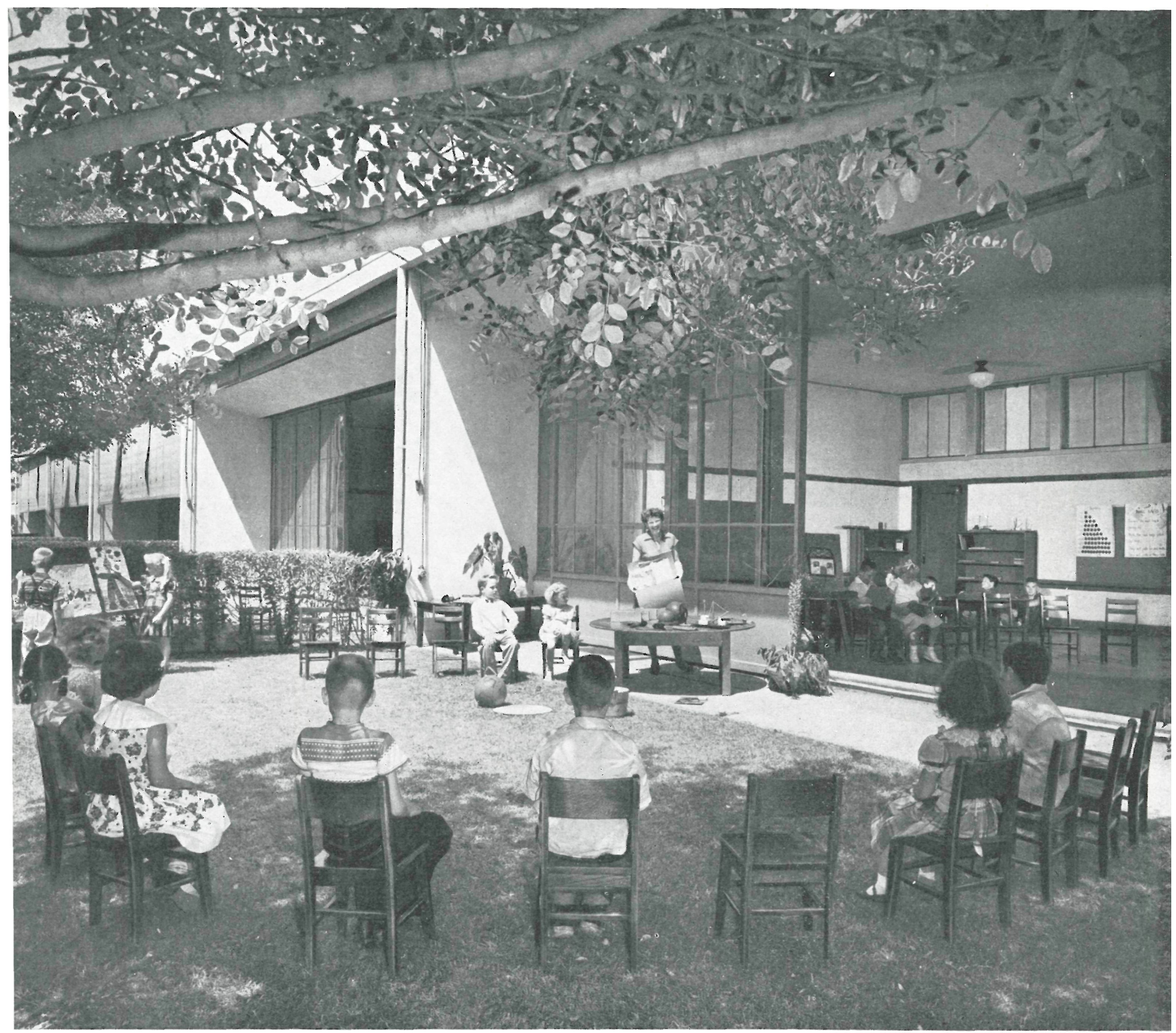

\title{
proyectar: instrumento de supervivencia
}

$100 \cdot 25$

;cuela Corona, en Bell, Calirnia (1935). En Estados UniS se emplea por primera vez a puerta corredera de cristal, e sirve de enlace y separación rior.
La capacidad de proyectar no es una adquisición del progreso humann, ni un inquilino recién llegado a nuestra interioridad. Es una función original, primaria y orgánica de nuestra extraña cabeza, que sobrepasa en desarrollo a la de los más evolucionados seres vivos. Somos seres dotados para la anticipación, y para la aplicación práctica de esa anticipación. De acuerdo con ello, proyectamos de antemano todas nuestras situaciones o-cuando menos-importantes fragmentos de ellas. 


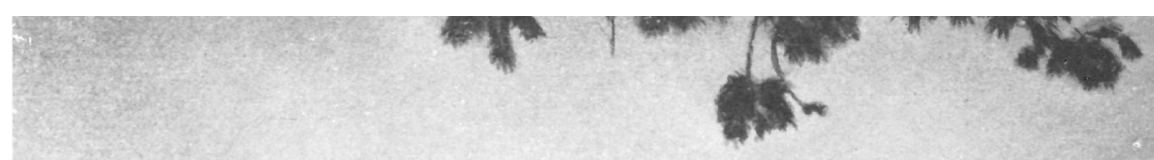

$\alpha$

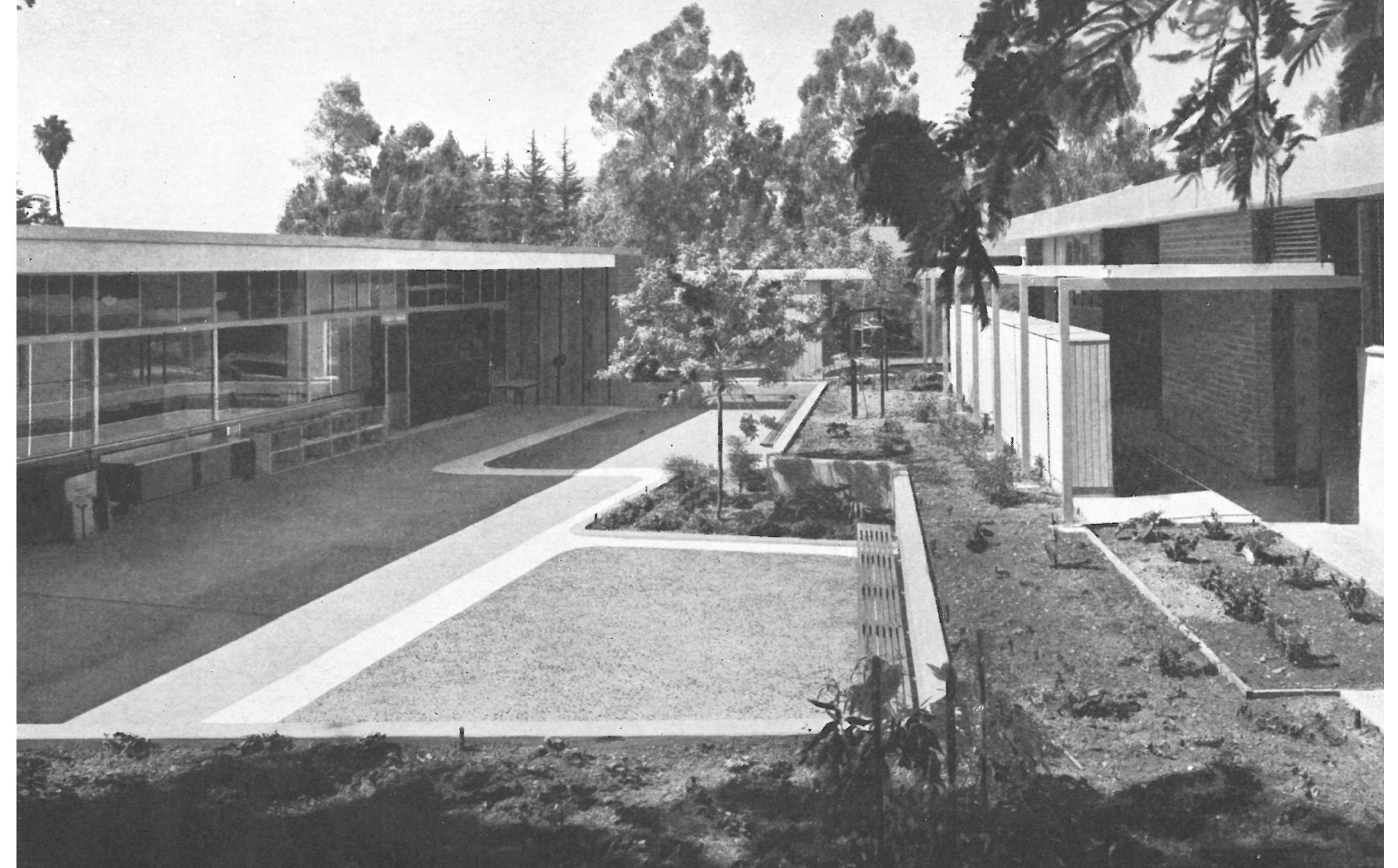

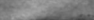

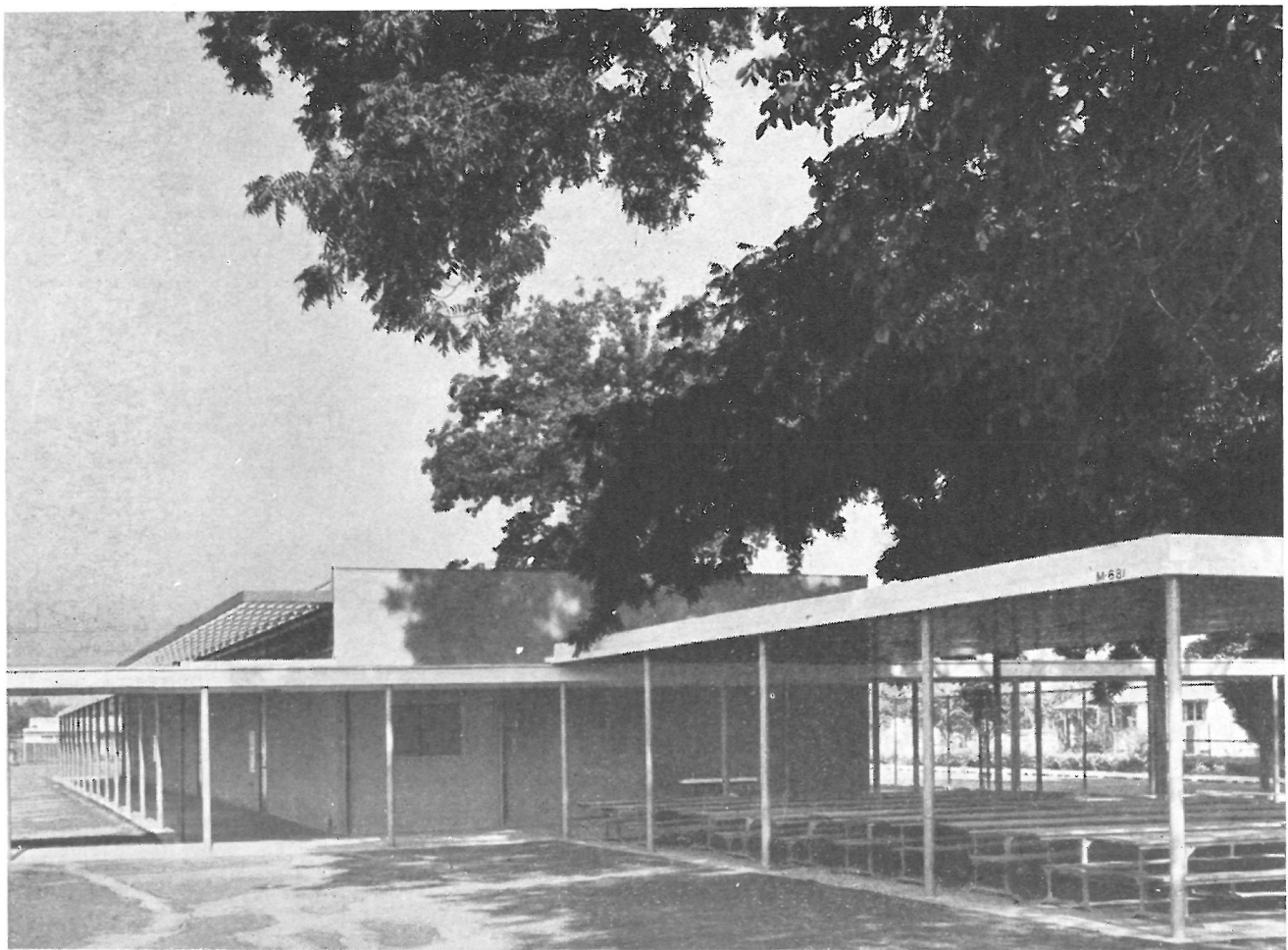


La elección de nuestros proyectos es también privilegio de nuestra naturaleza. Precede incluso a la necesidad de realizar el proyecto. Las funciones orgánicas y naturales son, desde luego, imprescindibles para la supervivencia, pero en la mayoría de los casos no son conscientes, ¿dejan, por ello, de ser útiles?

Los negocios florecen, si saben ofrecer sus productos en zonas donde verdaderamente se necesitan. Esta necesidad puede ser consciente, o-siendo todavía inconsciente-puede provocarla el negociante.

Elevar una necesidad latente a la luz de la conciencia es la esencia del arte suave y difícil de vender, y de este arte depende-en definitiva-la distribución, la producción y el consumo de nuestra civilización industrializada. El vendedor ha de luchar con inteligencia y bravura, si los futuros compradores no conocen aún sus necesidades vivas, $\mathrm{y}$ ha de imponerles su sentido práctico de las exigencias orgánicas.

Parece extraño; pero las necesidades humanas no son fáciles de señalar, y las personas que podrían sacar gran provecho de conocimientos de este tipo saben pocas cosas y de un modo muy genérico. Necesitamos un aprendizaje profundo de las exigencias humanas o, cuando menos, algunos indicios sobre ellas.

Ser director de un negocio joven y moderno, no significa haberlo iniciado en una fecha reciente; significa llevarlo a cabo según necesidades reales y según informaciones actuales. Hemos creído durante demasiado tiempo que las únicas informaciones de interés y los únicos datos reales-dentro del mundo de los negocios-son los facilitados por una valoración tecnológica. Sólo de esta manera parecen tener sentido, en esta época nuestra, excesivamente industrializada, excesivamente práctica y excesivamente ocupada. Pero existen ya otras ciencias muy actuales, que se desarrollan a gran velocidad y que se dirigen con ejemplar decisión a la vida humana de los consumidores. Hoy día tenemos industrias de casas prefabricadas, de cepillos de dientes, de aviones y de toda clase de muebles fabricados en serie. Estos productos necesitan, evidentemente, un conocimiento previo del futuro consumidor, para adecuar a sus preferencias las características del objeto. Vender algo que con el tiempo resulte fastidioso, es perder un posible y seguro cliente.

En realidad, lo que hace falta es un conocimiento biológico del hombre relacionado con su actual civilización. Es decir, debemos ponernos en contacto con la zona más tranquila y feliz de la biología, de la esencia humana. He encontrado un nombre para esta manera de investigar, para esta nueva filosofía: "Realismo biológico".

Se trata de utilizar con realismo todas las informaciones que hoy podemos adquirir sobre cuáles son las necesidades íntimas y detalladas del hombre. Nuestro sistema intenta adecuar todos los objetos que deseamos manejar de una manera comercial, a los deseos y las peculiaridades de cada hombre. Estos deseos pueden ser los más dispares: deseo de locomoción, que necesitará barcos, aviones o automóviles; deseo de fundar un hogar, que necesitará casas y muebles determinados; deseo de comer, de beber y de ayunar, que necesitará alimentos envasados, botellas y paquetes de vitaminas.

Todas las consideraciones de estilo que mueven al proyectista para satisfacer el gusto del cliente, se relacionan - en lo fundamental-con los datos facilitados por la observación fisiológica y no-o en muy pequeña medida-con los datos que suministran otras ciencias del pasado. Biológicamente hablando, es normal que los cuerpos se cansen o caigan enfermos. Los artículos puestos a la venta terminan también por cansar, por pasarse de moda, por no responder a las necesidades de las nuevas condiciones de vida que continuamente se crean. Cuando esto ocurre, los almacenes se llenan de productos sin salida, y alguien poco responsable-el gerente, tal vez, o el inocente delegado de ventas-sufre las consecuencias de este fracaso. Sin embargo, el proyectista, que es el verdadero responsable, permanece invisible en el fondo del desastre, y nadie le suele pedir cuentas.

En cualquier actividad humana que necesite un proyecto previo-sea para la locomoción, para las propiedades plásticas de un producto, o, simplemente, para propaganda-es indispensable la buena información biológica y el profundo conocimiento de la realidad humana, de la humana condición.

Los objetos primarios que se utilizaron, el medio ambiente que rodeó al hombre durante los 100.000 primeros años de su existencia, era esencialmente "natural". No se empleó entonces ninguna campaña consciente para adecuar los productos a las necesidades orgánicas. Hoy hemos llegado a una fase, en la cual un porcentaje enorme de nuestro medio ambiente es artificial, creado por la producción humana y fabricado por industrias en serie. Seguramente, hasta un $90 \%$ de los objetos que a diario manejamos no se encuentran como tales en la naturaleza.

Nos hemos olvidado con frecuencia de que, bajo estas circunstancias, nuestros sentidos se estropean, nuestros nervios se cansan y nuestra organización fisiológica se resiente. El problema de cuáles son los usos apropiados de un objeto y las necesidades a las que este objeto debe dirigirse, tiene que entrar, de una vez para siempre, en la mentalidad de todo aquel que desee prosperar en un negocio. Esto es absolutamente necesario, si queremos que la especie humana no desaparezca de la tierra.

Hemos dividido, con manifiesta exageración, el mundo, en "útil" y "estético". En la naturaleza que nos rodea no existe tal dualismo. Nadie es capaz de decir dónde un árbol deja de ser hermoso para convertirse en práctico. Su constitución es completamente homogénea, y-precisamente por ello-convincente. Tampoco en nuestra naturaleza interior podemos realizar esta 
peligrosa separación. Tenemos millones de sentidos, frente a los cinco que señalaba la sicología tradicional. $Y$ en este campo de la percepción sensorial, los resultados de la investigación fisiológica aumentan cada año nuestros conocimientos y nuestro asombro. Sin embargo, entre todos los sentidos que ahora conocemos, no existe ninguno de la "belleza" ni de la "utilidad". Belleza y utilidad son simples formas vacias del lenguaje.

Todos los sentidos colaboran en una percepción perpetua e indivisible, que hoy se llama "stereognosis". No poseemos muchos datos para conocer esto a fondo, y permanecemos todavía bastante alejados del asunto. Pero que lo desconozcamos no significa que deje de preocuparnos. Es el coche que no hemos visto-y del cual, por tanto, somos inconscientes - el que nos mata; no el que conocemos perfectamente, el que llama nuestra atención desde muy lejos.

¿Qué es utilidad y qué es belleza en la silla de un hombre de negocios? ¿Dónde está la línea de separación entre una y otra? ¿Lo sabe el negociante, o no tiene tiempo de reconocer la inexistencia de tal separación?

Pongamos otro ejemplo. Ante nuestros ojos, un hombre se sienta confortablemente en su silla mientras habla con un visitante. Se inclina sobre su escritorio, coge el teléfono con una mano, y escribe unas palabras con la otra. Al mismo tiempo, aprieta el conmutador del magnetofón o del micrófono. Mientras realiza todas estas operaciones, la iluminación, el aire acondicionado, el tratamiento acústico del techo, es decir, todas las mejoras que el proyectista ha ideado para su comodidad, le ayudan a vivir durante muchos años y evitan que vaya a parar a las manos de un cardiólogo o de un especialista en malestares nerviosos. La instalación de su oficina es, al mismo tiempo, medicina preventiva e ingeniería eficaz.

No cabe duda de que podemos investigar si este oficinista se siente cómodo o no, si rinde todas sus posibilidades o las desaprovecha, si funciona a la perfección o no. La forma, altura, elasticidad o tamaño de su silla, estimula continuamente su actividad sensorial; asimismo, el color y la estructura. Cuando está sentado y se mueve, los sentidos interiores registran la presión mutua entre músculos e intestinos. Nuestro sentido interior del equilibrio (que reside en el oído) se esfuerza continuamente para resistir la atracción de la gravedad, y jamás abandona esta oscura lucha, mientras su dueño trabaja y se afana, atendiendo al teléfono, hablando, escuchando o escribiendo. Las puntas de sus dedos tocan la mesa, la tapicería de la silla, o el cenicero; su oído goza del agradable silencio proporcionado por las placas acústicas del techo, que disminuyen la reverberación del ruido. Sus emociones se tranquilizan de esta manera, y se equilibran mejor. La conversación discurre serena y plácida, sin necesidad de elevar el tono de la voz hasta un punto próximo a la ira. Podemos enfadarnos seriamente con alguien sólo por tener que hablar a gritos. Y no nos damos cuenta de que el arquitecto y el proyectista - que cobraron sus honorarios tiempo atrás-son los culpables de esta desavenencia. Las conversaciones pueden continuar con facilidad durante varias horas seguidas, si controlamos el aire que hemos de respirar, su constitución química, su contenido de humedad, sus factores térmicos, su movimiento suave sobre nuestra piel, en vez de la violenta corriente de aire que se produce al abrir la secretaria una puerta. Todo esto depende del proyecto que fué trazado en su día, aunque no nos demos mucha cuenta. Los ojos consumen aparentemente la mayor parte de nuestra actividad perceptiva, pero no debemos subestimar la importancia de los otros medios receptores, su especial sensibilidad, y la naturaleza complicada y fácilmente destruible de nuestro organismo.

Si el oficinista en su despacho es un consumidor que se puede interpretar fisiológicamente, y que es susceptible de un diagnóstico, la misma consideración merece el público colectivo que compra y consume determinados productos.

Así, el proyectista está sentado ante una tabla de conmutadores y puede iniciar o apagar millares de reacciones individuales, estropear el equilibrio interior del cual depende nuestro bienestar, o mejorar las condiciones de nuestro medio ambiente y de nuestra propia vida interior. Puede armonizar y facilitar los procesos biológicos que se desarrollan en nuestro interior. Para ello necesita un profundo conocimiento del hombre, obtenido con la ayuda de los más penetrantes medios de investígación que el progreso sea capaz de colocar en sus manos. Un proyectista moderno debe ser también un práctico de la biología. Las leyes que controlan las drogas, las medicinas y los alimentos son universalmente reconocidas, y ningún obrero consciente permanece en un trabajo donde se embala y se envasa veneno. Pero no sólo son peligrosas las cosas que se comen. Influencias nocivas penetran en nosotros desde todos los rincones, y aprovechan cualquier medio para minar nuestra resistencia. Los diversos productos de la industria moderna actúan-decisivamente y a todas horas-sobre las condiciones vitales de los hombres, de los clientes que en su día compraron dichos productos. $Y$ los clientes no deben agonizar lentamente bajo las ruedas de molino del progreso técnico, no deben terminar sus días en las antesalas de los siquiatras y especialistas nerviosos.

Si la producción, fabricación y distribución de las industrias modernas no sigue las normas del Realismo Biológico, la raza humana-envuelta por un peligroso y superficial medio ambiente-está en trance de desaparición. $Y$, por supuesto, el negocio perecerá también con la humanidad. La supervivencia de ambos está en función de la inteligencia y buena voluntad del proyectista. $Y$ el arquitecto es el hombre que desde los tiempos más antiguos, y de una manera perfectamente consciente y organizada, se ocupa de proyectar, aunque posiblemente las Reglas de su profesión no hayan alcanzado todavía su madurez. La actividad constructiva desnaturaliza grandes porciones de la escena natural, y rodea al ser humano de materiales artificiales, que pueden convertirse en un chaleco de fuerza, o pueden ser la mejor ayuda para desarrollar al extremo nuestras posibilidades, por encima del actual desbarajuste tecnológico de nuestra civilización. 


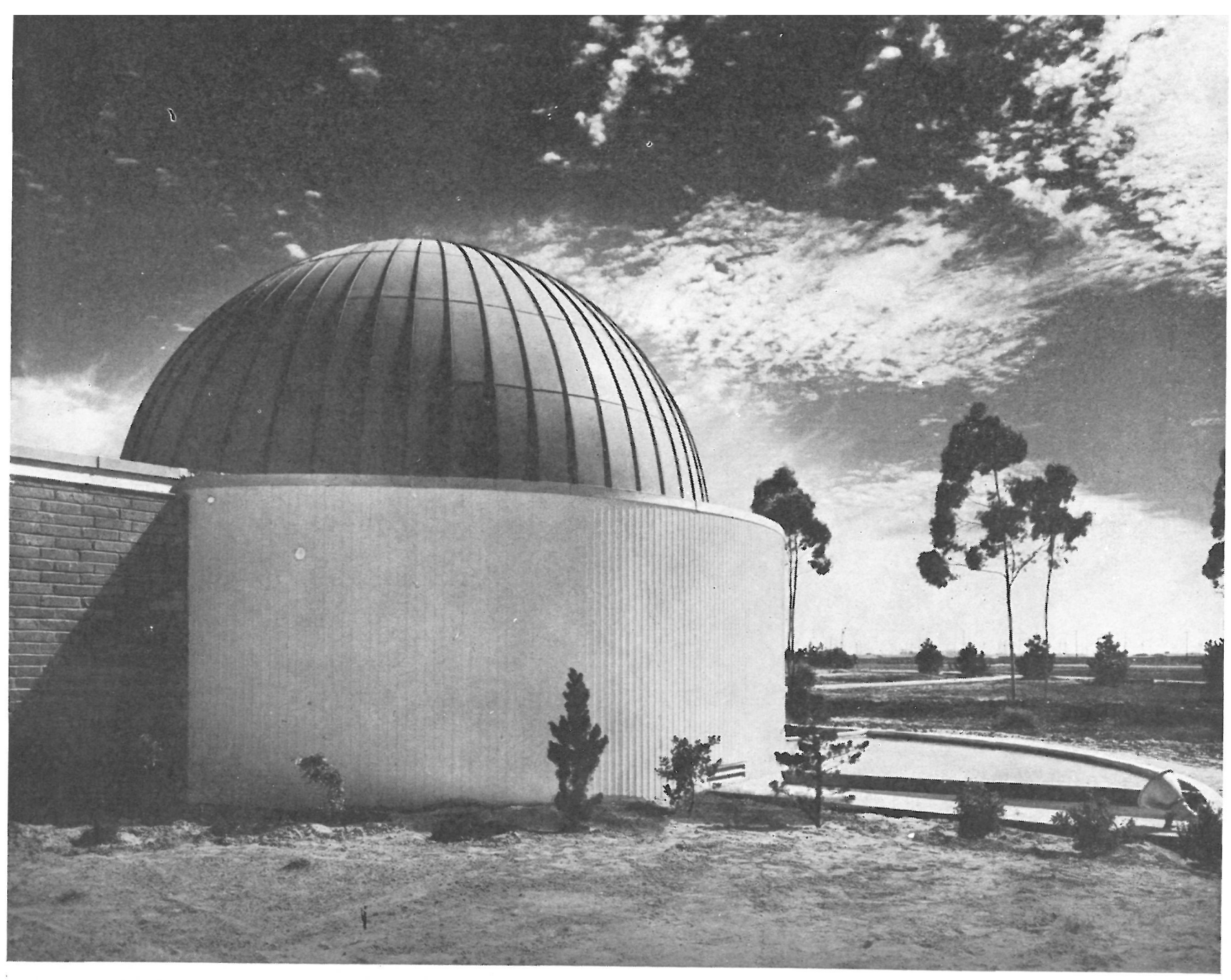

ige Coost

ge, Costo

ग, Califor.

ficio Cien-

y Audito.

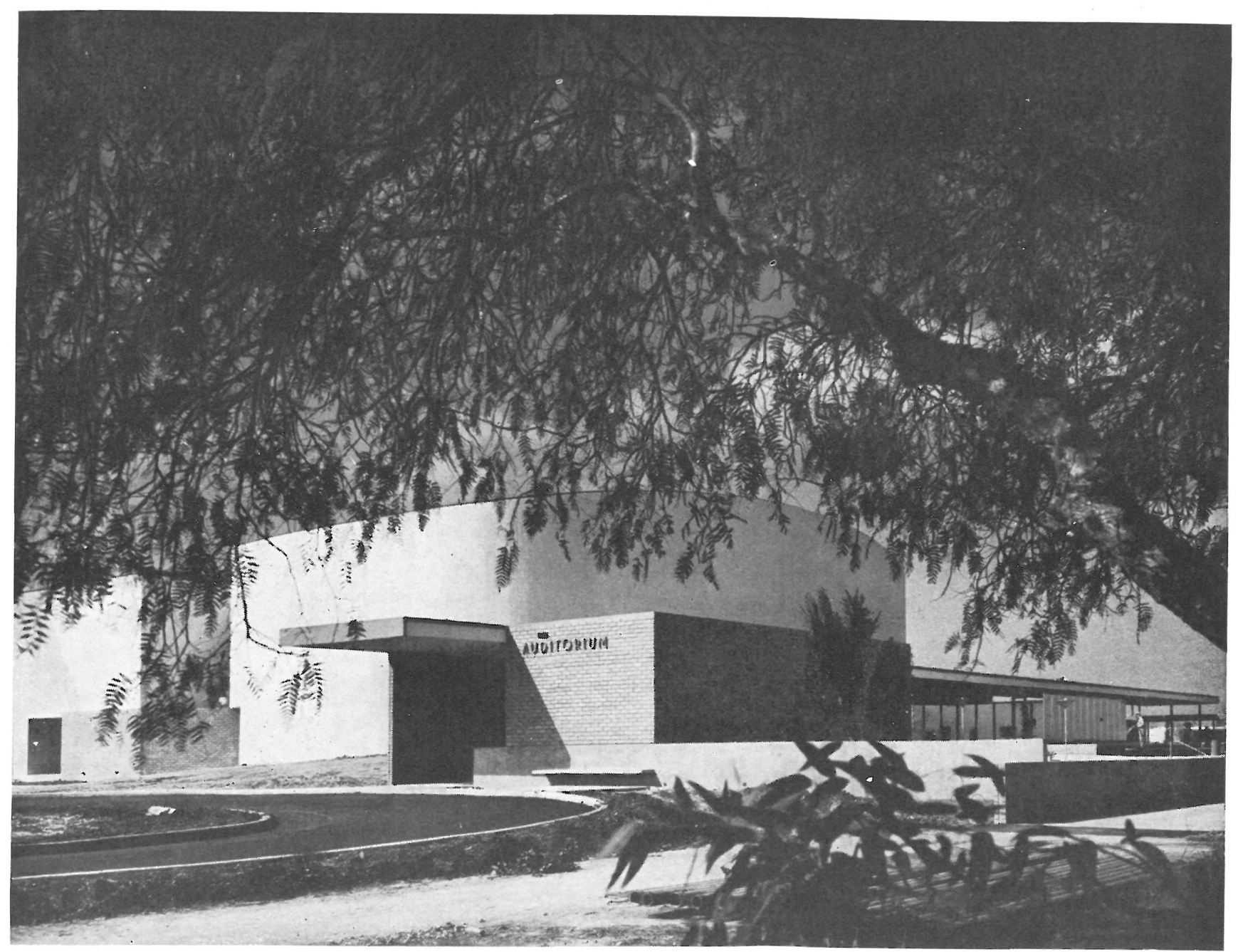




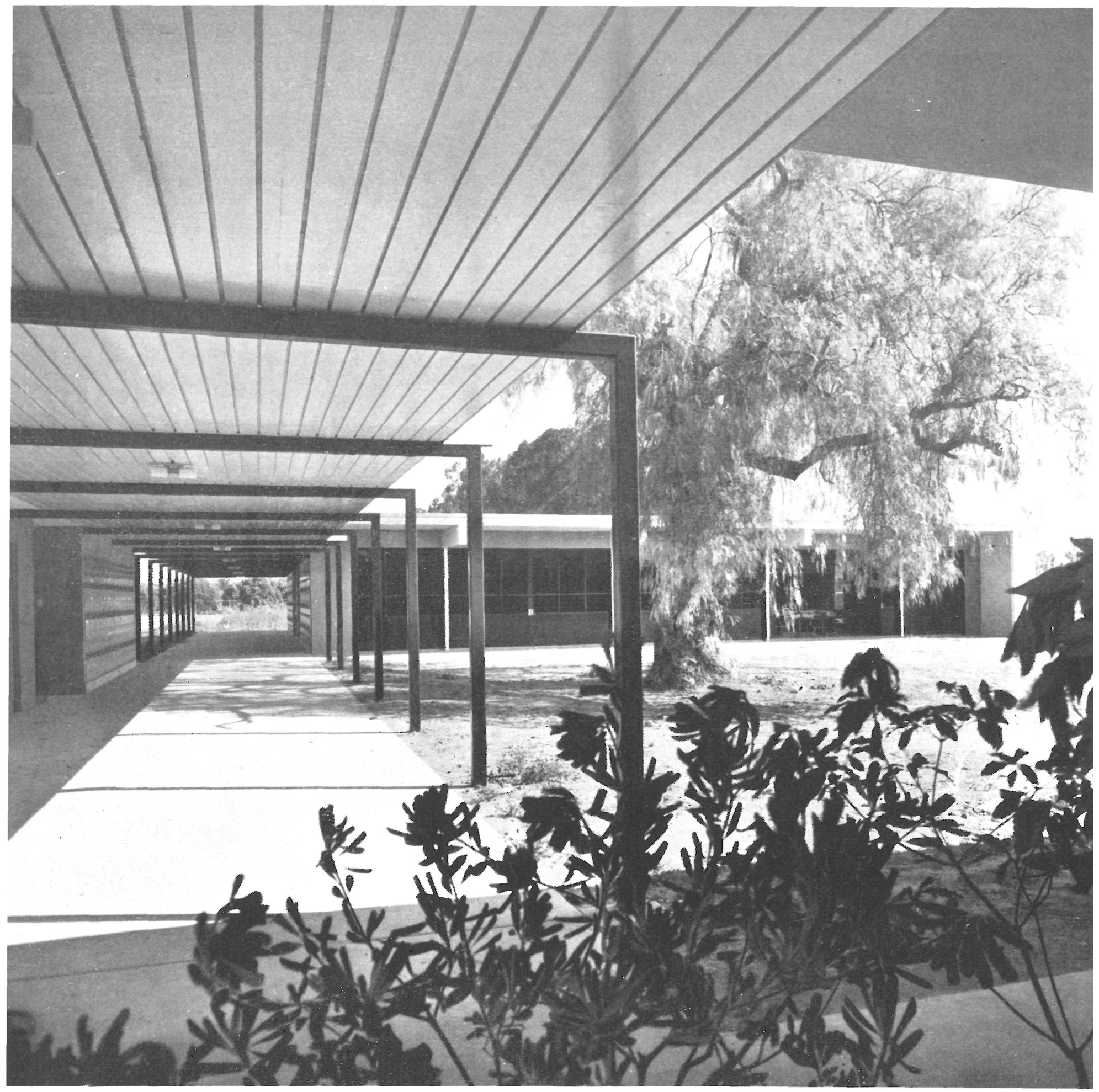

Si el arquitecto fuera capaz de sobrepasar el juego inocente e ignorante de las formas y de los colores, si fuera capaz de encontrar el aspecto trascendente de las simples colecciones técnicas de elementos, estructuras, materiales y dispositivos prefabricados, y si-sobre todoalguno explicara al joven arquitecto que inicia su carrera dónde residen las causas del malestar humano, y dónde las del bienestar, entonces él-el arquitecto, convertido casi en un biólogo profundo, inteligente, enamorado de su labor-, entonces él, digo, llegaría a ser un hombre nuevo, necesario, eficaz, útil, importante, hermano de los que sufren y los que aman. Su contribución al progreso humano sería muy distinta de la del ingeniero, que no estudia las fuerzas y las tracciones de los nervios. El arquitecto del mañana será-si aplica estos conceptos-un verdadero benefactor de la especie, de esta humana especie que tanto se enorgullece hoy por sus supuestos, gloriosos, indiscutidos y patentados adelantos técnicos.

Pórticos de enlace de las distin. tas unidades docentes, que sir. ven de zona de juego en los días de lluvia, en una escuela de en. señanza media en Alamitos Garden Grover, California. 